\title{
Music training and empathy positively impact adults' sensitivity to infant distress
}

\section{Christine E. Parsons ${ }^{1,2 \dagger}$, Katherine S. Young ${ }^{1,2,3}{ }^{1}$, Else-Marie E. Jegind ${ }^{2}$, Peter Vuust ${ }^{2,4}$, Alan Stein ${ }^{1}$ and Morten L. Kringelbach ${ }^{1,2 *}$}

1 Department of Psychiatry, University of Oxford, Oxford, UK

${ }^{2}$ Centre of Functionally Integrative Neuroscience, Aarhus University, Aarhus, Denmark

${ }^{3}$ Department of Psychology, University of California at Los Angeles, Los Angeles, CA, USA

${ }^{4}$ The Royal Academy of Music, Aarhus/Aalborg, Denmark

\section{Edited by:}

Jean Decety, University of Chicago, USA

\section{Reviewed by:}

Peter A. Bos, Utrecht University, Netherlands

Ruth Wells, University of Sydney, Australia

\section{${ }^{*}$ Correspondence}

Morten L. Kringelbach, Department of Psychiatry, University of Oxford, Warneford Hospital, Oxford OX3

7JX, UK

e-mail: morten.kringelbach@psych. ox.ac.uk

${ }^{\dagger}$ These authors have contributed equally to this work.
Crying is the most powerful auditory signal of infant need. Adults' ability to perceive and respond to crying is important for infant survival and in the provision of care. This study investigated a number of listener variables that might impact on adults' perception of infant cry distress, namely parental status, musical training, and empathy. Sensitivity to infant distress was tested using a previously validated task, which experimentally manipulated distress by varying the pitch of infant cries. This task required that participants discriminate between pitch differences and interpret these as differences in infant distress. Parents with musical training showed a significant advantage on this task when compared with parents without. The extent of the advantage was correlated with the amount of self-reported musical training. For non-parents, individual differences in empathy were associated with task performance, with higher empathy scores corresponding to greater sensitivity to infant distress. We suggest that sensitivity to infant distress can be impacted by a number of listener variables, and may be amenable to training.

Keywords: parenting, crying, vocalization, music, empathy, emotion perception, parent-infant, vocal emotion perception

\section{INTRODUCTION}

Crying is a powerful communicator of infant need. Parents' capacity to perceive and respond to infant communication is an important determinant of the quality of early care (Parsons et al., 2010). This is important because there is good evidence that early caregiving shapes infant development across a range of domains including cognitive, social, and emotional functioning (Raviv et al., 2004; Sohr-Preston and Scaramella, 2006; Stein et al., 2008). Of all of the typical infant behaviors, crying presents a substantial challenge to parents. Hearing the sound is associated with a cascade of neuroendocrinal events, most notably autonomic arousal and brainstem activity (Parsons et al., 2012, 2013c) Crying can cause parents substantial distress, especially when perceived as excessive or difficult to sooth (Miller et al., 1993) and is associated with parental sense of competence (e.g., Stifter et al., 2003).

The capacity to respond appropriately to infant crying depends on basic perceptual abilities. A number of acoustic parameters within infant cries have been identified that provide information as to the infant's current physiological and affective state. These include pitch, duration, onset, and pauses (for review, see Soltis, 2004). Of these, pitch has been identified as the key acoustic factor affecting caregiver perceptions and responses (LaGasse et al., 2005). Evidence for the role of pitch as a marker of infant distress comes from studies examining adults' perception of infant emotion in natural contexts (e.g., Zeskind and Collins, 1987), studies that experimentally manipulate pitch and measure adults' responses (e.g., Zeskind et al., 1995) and studies of infant pain responses (e.g., Porges, 1995).

\section{PITCH AND INFANT DISTRESS}

While much of the evidence for pitch as a marker of infant distress comes from studies manipulating cry acoustics, there is some work examining naturally occurring crying. For instance, in one study of caregiving behavior in a daycare setting, adults were found to respond with greater urgency and make additional efforts to soothe high pitched crying when compared to lower pitched crying (Zeskind and Collins, 1987). Another study found that the cries of high medical complication infants were characterized by a higher pitch compared with low complication infants and rated as more urgent, aversive, grating, sick, distressing, piercing, and 'discomforting' by adult listeners (Zeskind and Lester, 1978). Finally, one study examined a number of acoustic parameters of infant crying and found that pitch was the best predictor of adults' perception of distress (Zeskind and Marshall, 1988).

A body of laboratory studies have provided clear evidence that experimental manipulations of pitch result in cries being perceived as increasingly arousing, urgent, aversive, and sick sounding as pitch increases (Zeskind et al., 1995; Dessureau et al., 1998). Some studies manipulated the infant cry pitch by specific frequency amounts (e.g., $100 \mathrm{~Hz}$; Zeskind et al., 1995), or specific semitone amounts (Young et al., 2012) or percentage of 
overall pitch (Protopapas and Eimas, 1997), but all have yielded consistent results.

There are clear physiological mechanisms linking pitch, and changes in pitch, to infant affective state (Soltis, 2004). The association between pitch and distress is mediated by the vagus, in particular the branch of the vagus linking the nucleus ambiguous to the larynx. During acute stress (e.g., pain or fear), the sympathetic nervous system is activated and the parasympathetic nervous system is attenuated. As part of the parasympathetic withdrawal, vagal tone is lowered, eliciting a number of physiological adaptations (Porter et al., 1988; Porges, 1995, 1997). Among these adaptations, muscle tension is crucial, resulting in changes in the pitch of vocalizations. Greater infant arousal and distress is associated with increased tension in the vocal chords, producing higher pitched vocalizations (Porter et al., 1988; Porges, 1995).

Observational studies of infant pain response and arousal provide further confirmation of this physiological link. For instance, cry pitch has been shown to directly relate to parasympathetic activity in the child (Porter et al., 1988; Green et al., 2000). In addition, pitch is higher when infants cry in response to painful medical procedures (injection) compared to non-painful procedures (alcohol rub; Grunau et al., 1990). Finally, cries during invasive circumcisions are higher in pitch than cries during less invasive circumcisions (Porter et al., 1986). These converging lines of evidence underline the significance of pitch as a marker of infant distress. It would seem important, therefore, that adults be able to perceive and respond to cry pitch. Recent work has attempted to identify factors that might negatively impact infant cry perception generally, and also specifically in relation to pitch. There is some evidence for the effects of illegal drug use (Schuetze and Zeskind, 2003), teenage motherhood (Giardino et al., 2008), and depression, with depression being the most studied factor. Several studies have reported that mothers with depression are less likely to initiate appropriate caregiving responses to their infant's cries than healthy mothers (Bettes, 1988; Murray et al., 1993; Schuetze and Zeskind, 2001). While there are a number of plausible features of depression that might impact on a mother's response to her infant, it has been suggested that mothers with depression might have decreased sensitivity to basic perceptual features of these sounds, particularly pitch (Zeskind et al., 1995; Donovan et al., 1998) which may impair initiation of responding. This suggestion is supported by work showing decreased ability to discriminate distress, as manipulated by pitch, in adults with depression and no music training (Young et al., 2012). Perceptual difficulties, which may be linked to other core features of depression such as motivation and biased information processing, might be important in mother-infant interactions in depression.

\section{PARENTAL STATUS AND RESPONDING TO CRYING}

There has been a general assumption that becoming a parent might positively impact adults' responses to infant cries. Studies to date have yielded somewhat divergent results. For instance, there is some evidence that parents rate infant crying as less distressed (Irwin, 2003) and less aversive than non-parents (Zeskind and Lester, 1978), and respond with less cardiac reactivity (Out et al., 2010). It has also been reported that mothers tend to respond with greater sympathy and alertness to infant cries compared to non-mothers (Stallings et al., 2001).

However, other studies have reported no difference between mothers and non-mothers on measures of mean heart rate in response to infant crying (Hall and Morsbach, 1989), and that non-parents are more similar in cardiac response to experienced parents than new parents (Boukydis and Burgess, 1982). Another study reported that parents and non-parents did not differ in their ratings of infant distress, empathic concern, caregiving intention (Lin and McFatter, 2012) or motor movements in response to infant cries (Parsons et al., 2012). Furthermore, brain imaging studies have not yet provided a clear picture (Parsons et al., 2013a,b). One fMRI study reported stronger activation to infant crying in the amygdala and limbic areas in parents compared to non-parents (Seifritz et al., 2003), but another recent study reported no such difference (De Pisapia et al., 2013).

\section{EMPATHY AND CAREGIVING}

The reasons for these discrepant findings are unclear, but may be related to individual differences in the participant groups included in these studies. For instance, individual differences in adults' own early life experiences have also been shown to moderate responses to infant cues (Bhandari et al., 2014a,b). Furthermore, it has been argued that individual differences in dispositional empathy might moderate caregiving responses to distressed others (Lockwood et al., 2013). However, studies of the effects of parenthood have not yet addressed individual differences in empathy directly. This seems important because recent models of empathy have emphasized its role in motivating parental caregiving behavior (Decety and Cowell, 2014). There is substantial overlap in the neurochemical underpinnings of caregiving behavior and empathic responding. Oxytocin, in particular, has been strongly linked to both caregiving (Rilling and Young, 2014; Bakermans-Kranenburg and van Ijzendoorn, 2008; Gordon et al., 2010; Feldman et al., 2013; but effects are not necessarily straightforward, Voorthuis et al., 2014) and empathic responding in humans (Rodrigues et al., 2009; Hurlemann et al., 2010).

\section{MUSICAL TRAINING: AN ADVANTAGE IN EMOTION PROCESSING?}

Another plausible factor that might impact on the perception of infant crying is musical experience. Emotion perception in vocal sounds and music depend on shared acoustic and neural mechanisms (Nair, 2002; Scherer, 2003). Numerous studies have shown that musicians have heightened sensitivity to emotion in speech compared to non-musicians (for review, see Kraus and Chandrasekaran, 2010) and emerging evidence suggests that this sensitivity extends to non-speech vocalizations also (Strait et al., 2009; Young et al., 2012). Indeed, pitch processing is one acoustic component where musicians show clear advantages over nonmusicians (Magne et al., 2006; Musacchia et al., 2007; Vuust et al., 2012), which may be especially helpful for responding to infant crying.

In the current study, we aimed to examine the effects of parental status, empathy, and musical training on the perception of distress in infant cries. While previous work has tended to examine factors such as parental status in isolation, we tested 
whether individual differences in dispositional empathy and years of musical training might also be important. While one previous study demonstrated the importance of musical training in adults experiencing current psychopathology (Young et al., 2012), we tested whether it might be of relevance in healthy adults. Using a two-alternative forced choice (2AFC) task, we asked participants to identify the more distressed of two infant cries. The two sounds differed only with respect to their pitch, which was systematically altered by varying amounts (as described in Young et al., 2012). We expected that (i) parents would show greater sensitivity to infant distress compared with nonparents, (ii) musicians would show greater sensitivity than nonmusicians, and (iii) dispositional empathy would correlate with sensitivity.

\section{MATERIALS AND METHODS}

Ethical approval for the study was granted by the Ethics Committee of Central Region Denmark.

\section{PARTICIPANTS}

Participants were recruited from the general community in Aarhus using posters, online advertisements, and social media. All provided written informed consent for participation. Inclusion criteria for participation were: not currently experiencing any psychological or physical conditions, no problems with hearing, normal vision or vision correct to normal. Fifty-seven women and 52 men participated, of whom 29 were mothers and 25 were fathers. All of the fathers and mothers had infants aged less than 18 months $(M=8.1$ months, $\mathrm{SD}=4.43)$. A total of 109 men and women participated (see Table 1 for demographic information). Participants were aged between 21 and 39 years $(M=28.76$, $\mathrm{SD}=3.69$ ). For assessing music training, participants were asked "Have you received formal education in music (excluding primary school)?" Music training was defined as individuals who reported receiving 4 or more years of formal music training (Young et al., 2012). Adults who reported having less than this were recorded as having "no music."

\section{QUESTIONNAIRES}

Measures of current depressive symptoms and empathy were obtained using Beck Depression Inventory-Second Edition (BDIII) and the Empathy Quotient (EQ). The BDI-II is a 21-item questionnaire, with each item scored on a 4-point scale indicating the presence and severity of symptoms (Beck et al., 1996). It is one of the most widely used measures of depression symptoms. Recent reviews indicate that it has high internal consistency and good test-retest reliability (consistency, 0.9 , retest reliability ranges from 0.73 to 0.96 ; Wang and Gorenstein, 2013).

The EQ is also a widely used questionnaire (Baron-Cohen and Wheelwright, 2004), comprising 60 items (40 empathy related, 20 fillers), each scored on a 4-point scale. Each item linked to empathy is then associated with a score $(0,1$, or 2$)$, and a total score is computed (0-80). Three 5-item subscales (0-10) have been identified, cognitive empathy, emotional reactivity and social skills (Muncer and Ling, 2006). The EQ has high internal consistency (Cronbach's alphas $>0.88$ in both cases) and low levels of skew and kurtosis (Wakabayashi et al., 2006). The EQ questionnaire also shows moderate associations with the Interpersonal Reactivity Index (IRI; Davis, 1980), suggesting concurrent validity (Lawrence et al., 2004). EQ scores have also been shown to correlate with performance on tasks measuring non-verbal mental inference (the "Eyes" task; Lawrence et al., 2004), accuracy perceiving face gender (Penton-Voak et al., 2007) and face identify (Bate et al., 2010).

\section{STIMULI}

Fifteen digital recordings of infant cry bursts from the OxVoc database (Parsons et al., 2014b) were used in this study. Audio recordings in this database were collected from nine healthy infants (age $M=6.7$ months, $\mathrm{SD}=0.9$ ) filmed in their own homes during a play and feeding session with a caregiver. Individual cry clips were digitally altered to increase and decrease overall pitch by $0.25,0.5,1$, and 2 semitones, using Adobe Audition software (CS5.5 v4.0; same procedure as in Young et al., 2012). This corresponded to changes in fundamental frequency of approximately $5-10,12-17,25-30$, and 50-60 Hz, respectively. Clips of the same cry burst at different pitches were presented in pairs that differed by 0.5 semitones $(-0.25$ vs. +0.25$), 1$ semitone $(-0.5$ vs. +0.5$), 2$ semitones ( -1 vs. +1$)$, and 4 semitones $(-2$ vs. +2$)$.

\section{PROCEDURE}

In the 2AFC task, participants listened to two clips successively and were asked to choose which cry burst "sounded more distressed." Each pitch difference $(0.5,1,2$, or 4 semitones) was presented for each of the 15 vocalizations, resulting in a total of 60 trials. Sounds were presented using Presentation software (Version 14.4, Neurobehavioral Systems, Inc., www.neurobs.com; 24-bit Realtek High Definition Audio sound card) through Sony in-ear earphones (MDR-EX77LP) using a desktop computer. To facilitate ease of responding, sounds were presented alongside an image of an unfamiliar fractal (a fragmented geometric shape) in one of two locations. Accuracy

Table 1 | Participant demographic information by parental status and music training.

\begin{tabular}{|c|c|c|c|c|}
\hline & \multicolumn{2}{|c|}{ Parents $(N=54)$} & \multicolumn{2}{|c|}{ Non-parent $(N=55)$} \\
\hline & Music $(N=25)$ & No music $(N=29)$ & Music $(N=26)$ & No music $(N=29)$ \\
\hline Mean years of music (SD) & $6.80(4.46)$ & & $6.6(4.62)$ & \\
\hline Mean BDI score (SD) & $4.48(3.8)$ & $3.28(2.86)$ & $2.92(2.94)$ & $2.76(2.57)$ \\
\hline Mean EQ score (SD) & $49.96(8.67)$ & $49.10(12.11)$ & $44(10.38)$ & $50.48(8.29)$ \\
\hline
\end{tabular}

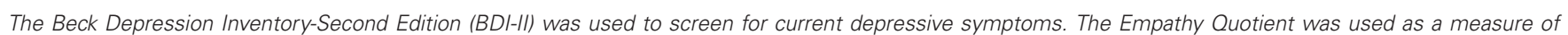
self-reported dispositional empathy. 
was defined as the number of trials in which participants identified the higher-pitched clip as "more distressed." The order of whether the correct clip was presented first or second was randomized.

\section{RESULTS}

Figure 1 presents the percentage of correct trials at the four levels of pitch difference for the parent and non-parent groups separately, comparing those with and without music training. There were no significant differences between men and women overall ( $p$-values $>0.42$ ). Therefore, results for the men and women are presented together.

A mixed ANOVA, with pitch difference as the within-subjects factor, parental status and music training as the between-subjects factors was used to examine participant accuracy scores. The variance in accuracy scores across the groups was found to be similar at all four difficulty levels of the task using Levene's test

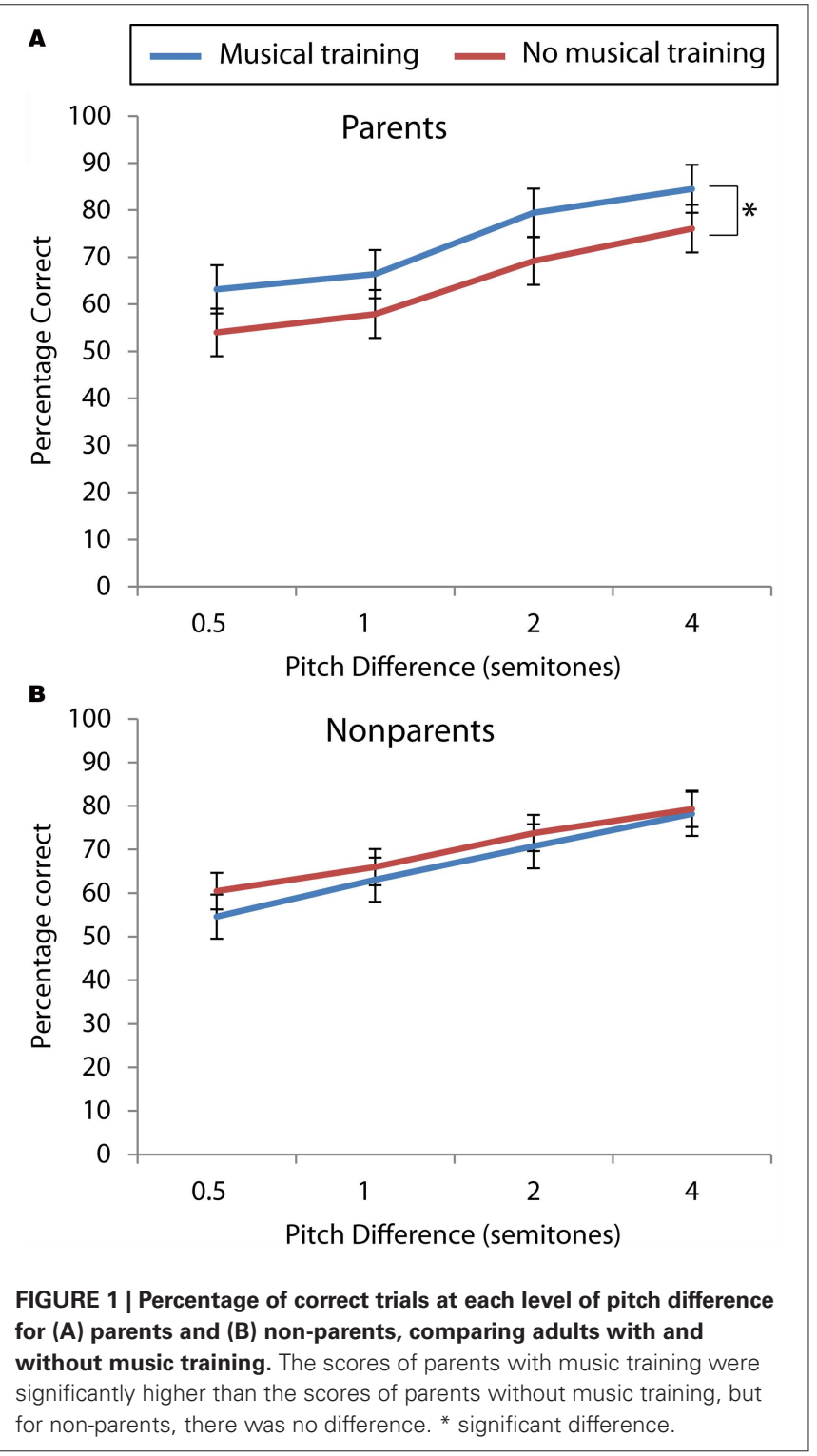

( $p$-values $>0.16)$. There was a significant effect of pitch level $[F(3,193)=54.68, p<0.0001]$, with scores being highest on the largest pitch difference ( 2 semitones) and lowest for the smallest difference (0.25 semitone). There was a significant interaction between parental status and music training $[F(1,104)=9.92$, $p<0.002]$, where parents with music training performed better than those without, but non-parents with and without music training showed no difference. None of the other main effects or interaction effects reached significance (all $p$-values $>0.14$ ).

\section{PARENTS WITH AND WITHOUT MUSIC TRAINING}

Taking a total accuracy score (four levels summed, scores out of $60)$, parents with music training performed better $(M=44.04$, $\mathrm{SD}=7.28)$ than parents without $[M=38.3, \mathrm{SD}=5.63$; $t(52)=3.22, p<0.002]$. The difference between the two groups was significant at all four levels of the task (see Figure 1A). Furthermore, in parents the number of years of music training positively correlated with overall scores $(r=0.24, p<0.04)$ and scores at two levels of the task (2 semitone difference: $r=0.24$, $p<0.04$; 4 semitone difference: $r=0.26, p<0.03)$. However, this was not the case for non-parents.

\section{EMPATHY}

Table 2 presents correlations between participants' EQ scores and their performance on the distress detection task. Taking participants' total scores, EQ scores were positively correlated with task performance, $r=0.18, p=0.029$ (one-tailed test). None of the individual EQ subscales (Cognitive Empathy, Emotional Reactivity, Social Skills) were significantly correlated with accuracy on the task. Comparing correlations by parental status, the association between EQ scores and task accuracy appeared to be primarily driven by the non-parent group. For non-parents only, EQ was positively correlated with scores on the task overall, and at each level of the task (see Table 2). Examining the subscales of the EQ, Cognitive Empathy showed the strongest association with overall task performance $(r=0.355, p<0.004)$, but the other two subscales were also significantly correlated with performance (Emotional Reactivity, $r=0.3, p<0.01$; Social Skills, $r=0.25$, $p<0.03)$. For the parent group, EQ scores, or its subscales, did not correlate significantly with task performance.

\section{DISCUSSION}

This study examined factors that might impact perception of emotion in infant vocal cues. The listener variables examined were parental status, music training, and self-reported empathy. The

Table 2 | Results of correlation analyses of EQ scores with accuracy of performance on distress detection task.

\begin{tabular}{lcccccc}
\hline & \multicolumn{2}{c}{ Whole group } & \multicolumn{2}{c}{ Parent } & \multicolumn{2}{c}{ Non-parent } \\
\cline { 2 - 7 } Semitone difference & $\boldsymbol{r}$ & $\boldsymbol{p}$ & $\boldsymbol{r}$ & $\boldsymbol{p}$ & $\boldsymbol{r}$ & $\boldsymbol{p}$ \\
\hline 0.5 & 0.1 & 0.16 & 0.02 & 0.43 & $0.24^{*}$ & 0.04 \\
1 & 0.09 & 0.19 & 0.08 & 0.27 & $0.29^{*}$ & 0.02 \\
2 & 0.15 & 0.07 & 0.02 & 0.43 & $0.32^{*}$ & 0.01 \\
4 & 0.1 & 0.16 & 0.06 & 0.33 & $0.25^{*}$ & 0.03 \\
\hline
\end{tabular}

${ }^{*}$ Correlation is significant at the 0.05 level (one-tailed).

** Correlation is significant at the 0.01 level (one-tailed). 
task required that adults discriminate differences in pitch and interpret these as differences in infant distress. There were two main findings. First, among parents, those with music training showed greater sensitivity to distress in infant cries, as manipulated by pitch, than those without music training. Second, for adults who were not parents, empathy was positively associated with sensitivity to distress. Music training and empathy appeared to only have measurable effects in the parent and non-parent groups, respectively.

\section{MUSIC TRAINING}

For the parent group, even a relatively short duration of music training appeared to confer advantages in discriminating distress in infant cries. Music-trained participant groups in other studies often consist of professionals (e.g., Wallentin et al., 2010), those with a training onset early in life (e.g., Dohn et al., 2012) and/or a duration of longer than ten years (e.g., Schön et al., 2004; Thompson et al., 2004; Musacchia et al., 2007; Parbery-Clark et al., 2009). Adults categorized in this study as having music training had just 6-7 years on average, and there were no requirements as to its intensity, frequency, or onset. This is of interest because another study using approximately the same cutoff (6.5 years) did not find an advantage for those with music training on an emotional prosody task (Trimmer and Cuddy, 2008). It may be that for some tasks, a more extensive period of training is necessary, but for the current task, even this moderate amount of training yielded an advantage for the parent group tested.

Further to this, as might be expected, the longer the duration of music training reported, the bigger the performance advantage on the task. This music advantage in emotion discrimination, especially for those with extensive training, is consistent with previous work showing musician advantages for the recognition of emotion in non-music stimuli such as speech prosody (Lima and Castro, 2011), and pitch processing in speech (Schön et al., 2004; Marques et al., 2007).

The advantage found here for parents with music training is in line with descriptions of the inherent musical nature of mother-infant interactions. Infants are especially responsive to the richly intoned sounds of infant-directed speech (often called motherese), preferring them to the more muted tones of adultdirected speech (Soderstrom, 2007). Mothers across cultures, and indeed across historical periods, sing to their infants, and do so in a distinctive manner marked by high pitch, slow tempo, and emotional expressiveness (Trehub, 2001). This has led some to suggest that the regular, predictive "pulse" of music may act to enhance emotional co-ordination between mother and infant (Nakata and Trehub, 2004).

\section{EMPATHY}

In non-parents, individual differences in self-reported empathy were associated with sensitivity to infant distress. It might be that before parenthood, baseline individual differences in empathy are important in responding to infant distress. There is some emerging evidence that this is particularly the case for men responding to infant facial expressions (Parsons et al., under review). The current findings are also broadly consistent with work showing that individual differences in empathy moderate responses to crying adult faces (Lockwood et al., 2013). The lack of an effect of empathy for the parent group raises interesting questions. One possibility is that parenthood might act to heighten adults' empathic response to infants (for review, see Mascaro et al., 2014) rendering individual differences in empathy less critical.

\section{LIMITATIONS}

This study was cross-sectional, and the ideal design for investigating a variable like parenthood would be longitudinal. It would therefore be of interest to follow-up adults with and without music training, and varying in dispositional empathy, as they transition into parenthood. Furthermore, it remains to be shown as to whether differences in the discrimination of infant distress might translate into observable differences in caregiving behavior (for discussion, see Parsons et al., 2014a). Two studies have reported that adults wait longer to respond to infant cries that they had previously rated as sounding less distressed (Wood and Gustafson, 2001) and less aversive (Del Vecchio et al., 2009). One recent study has also shown that adults are more likely to indicate immediate and affectionate caregiving responses to high-pitched cries (Out et al., 2010). Clearly, additional work linking actual, observed parent-infant interactions with perceptions of infant expressions would be important. This would complement some of the recent innovative work examining hormonal changes associated with parenthood in both men and women (e.g., Feldman et al., 2013; Mascaro et al., 2014; Weisman et al., 2014).

We included just one question on participants' formal music training. Our current findings provide impetus for exploring the association between music experience and auditory emotion processing advantages. For instance, it might be that music experience, without formal training, may be sufficient for some individuals to show advantages. There may also be differences dependent on the type of instrument (voice, string, etc.), whether music practice is ongoing, or the age of onset of training. Furthermore, it is unclear why musical effects were apparent only in the parent group and not the non-parent group. Identification of the specifics of music training that confer measurable advantages on emotion processing tasks would be of great interest.

\section{FURTHER DIRECTIONS}

The finding of a music advantage for parents suggests that it might be possible to train adults to detect acoustic parameters communicating infant emotion. Pitch has been robustly demonstrated as an important indicator of distress in this study and in a body of other work (e.g., Dessureau et al., 1998; Schuetze and Zeskind, 2001; Soltis, 2004). A number of studies have shown that it is possible to improve individuals' performance on pitch discrimination tasks following 30-min training sessions (Amitay et al., 2006a,b). Whether this improvement can generalize to other settings and sounds is currently being debated (Wright and Sabin, 2007).

Furthermore, being able to discriminate emotion accurately does not mean that sensitive, responsive behavior will ensue. However, of potential relevance here are the promising findings from studies of attention or cognitive bias modification training. One study found that training to improve facial emotion recognition can translate into therapeutically relevant effects that persist 
for at least two weeks (Penton-Voak et al., 2012). Larger scale studies with clinical populations are ongoing (e.g., Adams et al., 2013), but may provide further impetus for implementing emotion discrimination training. If such training is effective, it would be beneficial to parenting contexts because it could be used during pregnancy, and delivered automatically via computer, Internet or smartphone. Such training on emotion discrimination might be helpful in augmenting other early parenting interventions, which have good evidence bases, such as Video Feedback (e.g., Stein et al., 2006; Bakermans-Kranenburg et al., 2008; Lawrence et al., 2013).

\section{ACKNOWLEDGMENTS}

This work was supported by a Medical Research Council Studentship to Katherine S. Young and an ERC Consolidator Grant: CAREGIVING (n. 615539) to Morten L. Kringelbach along with funding from the TrygFonden Charitable Foundation. We are grateful to the Wellcome Trust for their support (grant no 090139). The authors would like to acknowledge Geraldine Parsons for comments on an earlier draft.

\section{REFERENCES}

Adams, S., Penton-Voak, I. S., Harmer, C. J., Holmes, E. A., and Munafò, M. R. (2013). Effects of emotion recognition training on mood among individuals with high levels of depressive symptoms: study protocol for a randomised controlled trial. Trials 14:161. doi: 10.1186/1745-6215-14-161

Amitay, S., Irwin, A., Hawkey, D. J. C., Cowan, J. A., and Moore, D. R. (2006a). A comparison of adaptive procedures for rapid and reliable threshold assessment and training in naive listeners. J. Acoust. Soc. Am. 119, 1616-1625. doi: $10.1121 / 1.2164988$

Amitay, S., Irwin, A., and Moore, D. R. (2006b). Discrimination learning induced by training with identical stimuli. Nat. Neurosci. 9, 1446-1448. doi: $10.1038 / \mathrm{nn} 1787$

Bakermans-Kranenburg, M. J., and van Ijzendoorn, M. H. (2008). Oxytocin receptor (OXTR) and serotonin transporter (5-HTT) genes associated with observed parenting. Soc. Cogn. Affect. Neurosci. 3, 128-134. doi: 10.1093/scan/ nsn004

Bakermans-Kranenburg, M. J., Van Ijzendoorn, M. H., Pijlman, F. T. A., Mesman, J., and Juffer, F. (2008). Experimental evidence for differential susceptibility: dopamine D4 receptor polymorphism (DRD4 VNTR) moderates intervention effects on toddlers' externalizing behavior in a randomized controlled trial. Dev. Psychol. 44, 293-300. doi: 10.1037/0012-1649.44.1.293

Baron-Cohen, S., and Wheelwright, S. (2004). The empathy quotient: an investigation of adults with Asperger syndrome or high functioning autism, and normal sex differences. J. Autism. Dev. Disord. 34, 163-175. doi: 10.1023/B:JADD.0000022607.19833.00

Bate, S., Parris, B., Haslam, C., and Kay, J. (2010). Socio-emotional functioning and face recognition ability in the normal population. Pers. Individ. Differ. 48, 239-242. doi: 10.1016/j.paid.2009.10.005

Beck, A. T., Steer, R. A., and Brown, G. K. (1996). Manual for the Beck Depression Inventory-II. San Antonio, TX: Psychological Corporation.

Bettes, B. A. (1988). Maternal depression and motherese: temporal and intonational features. Child Dev. 59, 1089-1096. doi: 10.2307/1130275

Bhandari, R., Bakermans-Kranenburg, M. J., Van Der Veen, R., Parsons, C. E., Young, K. S., Grewen, K. M., et al. (2014a). Salivary oxytocin mediates the association between emotional maltreatment and responses to emotional infant faces. Physiol. Behav. 131, 123-128. doi: 10.1016/j.physbeh.2014.04.028

Bhandari, R., Van Der Veen, R., Parsons, C. E., Young, K. S., Voorthuis, A., Bakermans-Kranenburg, M. J., et al. (2014b). Effects of intranasal oxytocin administration on memory for infant cues: moderation by childhood emotional maltreatment. Soc. Neurosci. 9, 536-547. doi: 10.1080/17470919.2014. 932307

Boukydis, C. F., and Burgess, R. L. (1982). Adult physiological response to infant cries: effects of temperament of infant, parental status, and gender. Child Dev. 53, 1291-1298. doi: 10.2307/1129019
Davis, M. H. (1980). A multidimensional approach to individual differences in empathy. JSAS Catalog Sel. Doc. Psychol. 10, 85.

Del Vecchio, T., Walter, A., and O’Leary, S. G. (2009). Affective and physiological factors predicting maternal response to infant crying. Infant Behav. Dev. 32, 117-122. doi: 10.1016/j.infbeh.2008.10.005

De Pisapia, N., Bornstein, M. H., Rigo, P., Esposito, G., De Falco, S., and Venuti, P. (2013). Sex differences in directional brain responses to infant hunger cries. Neuroreport 24, 142-146. doi: 10.1097/WNR.0b013e32835df4fa

Decety, J., and Cowell, J. M. (2014). The complex relation between morality and empathy. Trends Cogn. Sci. 18, 337-339. doi: 10.1016/j.tics.2014.04.008

Dessureau, B. K., Kurowski, C. O., and Thompson, N. S. (1998). A reassessment of the role of pitch and duration in adults' responses to infant crying. Infant Behav. Dev. 21, 367-371. doi: 10.1016/S0163-6383(98)90013-3

Dohn, A., Garza-Villarreal, E. A., Heaton, P., and Vuust, P. (2012). Do musicians with perfect pitch have more autism traits than musicians without perfect pitch? an empirical study. PLOS ONE 7:e37961. doi: 10.1371/journal.pone. 0037961

Donovan, W. L., Leavitt, L. A., and Walsh, R. O. (1998). Conflict and depression predict maternal sensitivity to infant cries. Infant Behav. Dev. 21, 505-517. doi: 10.1016/S0163-6383(98)90023-6

Feldman, R., Gordon, I., Influs, M., Gutbir, T., and Ebstein, R. P. (2013). Parental oxytocin and early caregiving jointly shape children's oxytocin response and social reciprocity. Neuropsychopharmacology 38, 1154-1162. doi: 10.1038/npp. 2013.22

Giardino, J., Gonzalez, A., Steiner, M., and Fleming, A. S. (2008). Effects of motherhood on physiological and subjective responses to infant cries in teenage mothers: a comparison with non-mothers and adult mothers. Horm. Behav. 53, 149-158. doi: 10.1016/j.yhbeh.2007.09.010

Gordon, I., Zagoory-Sharon, O., Leckman, J. F., and Feldman, R. (2010). Oxytocin and the development of parenting in humans. Biol. Psychiatry 68, 377-382. doi: 10.1016/j.biopsych.2010.02.005

Green, J. A., Irwin, J. R., and Gustafson, G. E. (2000). "Acoustic cry analysis, neonatal status and long-term developmental outcomes," in Crying as a Sign, a Symptom, and a Signal: Clinical, Emotional, and Developmental Aspects of Infant and Toddler Crying, Vol. 152, eds R. G. Barr, B. Hopkins, and J. A. Green (New York: Cambridge University Press), 137-156.

Grunau, R. V. E., Johnston, C. C., and Craig, K. D. (1990). Neonatal facial and cry responses to invasive and non-invasive procedures. Pain 42, 295-305. doi: 10.1016/0304-3959(90)91142-6

Hall, A. E., and Morsbach, G. (1989). Differential stress responses in mothers and non-mothers to infant crying. Stress Tension Control 3, 229-233. doi: 10.1007/978-1-4615-7915-1_24

Hurlemann, R., Patin, A., Onur, O. A., Cohen, M. X., Baumgartner, T., Metzler, S., et al. (2010). Oxytocin enhances amygdala-dependent, socially reinforced learning and emotional empathy in humans. J. Neurosci. 30, 4999-5007. doi: 10.1523/JNEUROSCI.5538-09.2010

Irwin, J. R. (2003). Parent and nonparent perception of the multimodal infant cry. Infancy 4, 503-516. doi: 10.1207/S15327078IN0404_06

Kraus, N., and Chandrasekaran, B. (2010). Music training for the development of auditory skills. Nat. Rev. Neurosci. 11, 599-605. doi: 10.1038/nrn2882

LaGasse, L. L., Neal, A. R., and Lester, B. M. (2005). Assessment of infant cry: acoustic cry analysis and parental perception. Ment. Retard. Dev. Disabil. Res. Rev. 11, 83-93. doi: 10.1002/mrdd.20050

Lawrence, E. J., Shaw, P., Baker, D., Baron-Cohen, S., and David, A. S. (2004). Measuring empathy: reliability and validity of the Empathy Quotient. Psychol. Med. 34, 911-919. doi: 10.1017/S0033291703001624

Lawrence, P. J., Davies, B., and Ramchandani, P. G. (2013). Using video feedback to improve early father-infant interaction: a pilot study. Clin. Child Psychol. Psychiatry 18, 61-71. doi: 10.1177/1359104512437210

Lima, C. F., and Castro, S. L. (2011). Speaking to the trained ear: musical expertise enhances the recognition of emotions in speech prosody. Emotion 11, 10211031. doi: 10.1037/a0024521

Lin, H.-C., and McFatter, R. (2012). Empathy and distress: two distinct but related emotions in response to infant crying. Infant Behav. Dev. 35, 887-897. doi: 10.1016/j.infbeh.2012.08.001

Lockwood, P., Millings, A., Hepper, E., and Rowe, A. C. (2013). If I cry, do you care? J. Individ. Differ. 34, 41-47. doi: 10.1027/1614-0001/a000098

Magne, C., Schon, D., and Besson, M. (2006). Musician children detect pitch violations in both music and language better than nonmusician children: 
behavioral and electrophysiological approaches. J. Cogn. Neurosci. 18, 199-211. doi: $10.1162 / 089892906775783660$

Marques, C., Moreno, S., Castro, S. L., and Besson, M. (2007). Musicians detect pitch violation in a foreign language better than nonmusicians: behavioral and electrophysiological evidence. J. Cogn. Neurosci. 19, 1453-1463. doi: 10.1162/jocn.2007.19.9.1453

Mascaro, J. S., Hackett, P. D., and Rilling, J. K. (2014). Differential neural responses to child and sexual stimuli in human fathers and non-fathers and their hormonal correlates. Psychoneuroendocrinology 46, 153-163. doi: 10.1016/j.psyneuen.2014.04.014

Miller, A. R., Barr, R. G., and Eaton, W. O. (1993). Crying and motor behavior of six-week-old infants and postpartum maternal mood. Pediatrics 92, 551-558.

Muncer, S. J., and Ling, J. (2006). Psychometric analysis of the empathy quotient (EQ) scale. Pers. Individ. Differ. 40, 1111-1119. doi: 10.1016/j.paid.2005. 09.020

Murray, L., Kempton, C., Woolgar, M., and Hooper, R. (1993). Depressed mothers' speech to their infants and its relation to infant gender and cognitive development. J. Child Psychol. Psychiatry 34, 1083-1101. doi: 10.1111/j.14697610.1993.tb01775.x

Musacchia, G., Sams, M., Skoe, E., and Kraus, N. (2007). Musicians have enhanced subcortical auditory and audiovisual processing of speech and music. Proc. Natl. Acad. Sci. U.S.A. 104, 15894-15898. doi: 10.1073/pnas.0701498104

Nair, D. (2002). "Expressive timing and perception of emotion in music: an fMRI study," in Proceedings of the 7th International Conference on Music Perception and Cognition, Vol. 627 (Adelaide: Causal Productions), 627-630.

Nakata, T., and Trehub, S. E. (2004). Infants' responsiveness to maternal speech and singing. Infant Behav. Dev. 27, 455-464. doi: 10.1016/j.infbeh.2004.03.002

Out, D., Pieper, S., Bakermans-Kranenburg, M. J., Zeskind, P. S., and Van Ijzendoorn, M. H. (2010). Intended sensitive and harsh caregiving responses to infant crying: the role of cry pitch and perceived urgency in an adult twin sample. Child Abuse Negl. 34, 863-873. doi: 10.1016/j.chiabu.2010.05.003

Parbery-Clark, A., Skoe, E., Lam, C., and Kraus, N. (2009). Musician enhancement for speech-In-noise. Ear Hear. 30, 653-661. doi: 10.1097/AUD 0b013e3181b412e9

Parsons, C. E., Stark, E. A., Young, K. S., Stein, A., and Kringelbach, M. L. (2013a). Understanding the human parental brain: a critical role of the orbitofrontal cortex. Soc. Neurosci. 8, 525-543. doi: 10.1080/17470919.2013.842610

Parsons, C. E., Young, K. S., Mohseni, H., Woolrich, M. W., Thomsen, K. R., Joensson, M., et al. (2013b). Minor structural abnormalities in the infant face disrupt neural processing: a unique window into early caregiving responses. Soc. Neurosci. 8, 268-274. doi: 10.1080/17470919.2013.795189

Parsons, C. E., Young, K. S., Joensson, M., Brattico, E., Hyam, J. A., Stein, A., et al. (2013c). Ready for action: a role for the human midbrain in responding to infant vocalizations. Soc. Cogn. Affect. Neurosci. 9, 977-984. doi: 10.1093/scan/ nst076

Parsons, C. E., Young, K. S., Bhandari, R., van Ijzendoorn, M. H., BakermansKranenburg, M. J., Stein, A., et al. (2014a). The bonnie baby: experimentally manipulated temperament affects perceived cuteness and motivation to view infant faces. Dev. Sci. 17, 257-269. doi: 10.1111/desc. 12112

Parsons, C. E., Young, K. S., Craske, M. G., Stein, A. L., and Kringelbach, M. L. (2014b). Introducing the oxford vocal (OxVoc) sounds database: a validated set of non-acted affective sounds from human infants, adults, and domestic animals. Front. Psychol. 5:562. doi: 10.3389/fpsyg.2014.00562

Parsons, C. E., Young, K. S., Murray, L., Stein, A., and Kringelbach, M. L. (2010). The functional neuroanatomy of the evolving parent-infant relationship. Prog. Neurobiol. 91, 220-241. doi: 10.1016/j.pneurobio.2010.03.001

Parsons, C. E., Young, K. S., Parsons, E., Stein, A., and Kringelbach, M. L. (2012). Listening to infant distress vocalizations enhances effortful motor performance. Acta Paediatr. Int. J. Paediatr. 101, e189-e191. doi: 10.1111/j.16512227.2011.02554.x

Penton-Voak, I. S., Allen, T., Morrison, E. R., Gralewski, L., and Campbell, N. (2007). Performance on a face perception task is associated with empathy quotient scores, but not systemizing scores or participant sex. Pers. Individ. Differ. 43, 2229-2236. doi: 10.1016/j.paid.2007.07.004

Penton-Voak, I. S., Bate, H., Lewis, G., and Munafò, M. R. (2012). Effects of emotion perception training on mood in undergraduate students: randomised controlled trial. Br. J. Psychiatry 201, 71-72. doi: 10.1192/bjp.bp.111.107086

Porges, S. W. (1995). Cardiac vagal tone: a physiological index of stress. Neurosci. Biobehav. Rev. 19, 225-233. doi: 10.1016/0149-7634(94)00066-A
Porges, S. W. (1997). Emotion: an evolutionary by-product of the neural regulation of the autonomic nervous system. Ann. N. Y. Acad. Sci. 807, 62-77. doi: 10.1111/j.1749-6632.1997.tb51913.x

Porter, F. L., Miller, R. H., and Marshall, R. E. (1986). Neonatal pain cries: effect of circumcision on acoustic features and perceived urgency. Child Dev. 57, 790802. doi: $10.2307 / 1130355$

Porter, F. L., Porges, S. W., and Marshall, R. E. (1988). Newborn pain cries and vagal tone: parallel changes in response to circumcision. Child Dev. 59, 495-505. doi: $10.2307 / 1130327$

Protopapas, A., and Eimas, P. D. (1997). Perceptual differences in infant cries revealed by modifications of acoustic features. J. Acoust. Soc. Am. 102, 37233734. doi: $10.1121 / 1.420403$

Raviv, T., Kessenich, M., and Morrison, F. J. (2004). A mediational model of the association between socioeconomic status and three-year-old language abilities: the role of parenting factors. Early Child. Res. Q. 19, 528-547. doi: 10.1016/j.ecresq.2004.10.007

Rilling, J. K., and Young, L. J. (2014). The biology of mammalian parenting and its effect on offspring social development. Science 345, 771-776. doi: $10.1126 /$ science. 1252723

Rodrigues, S. M., Saslow, L. R., Garcia, N., John, O. P., and Keltner, D. (2009). Oxytocin receptor genetic variation relates to empathy and stress reactivity in humans. Proc. Natl. Acad. Sci. U.S.A. 106, 21437-21441. doi: 10.1073/pnas.0909579106

Scherer, K. R. (2003). Vocal communication of emotion: a review of research paradigms. Speech Commun. 40, 227-256. doi: 10.1016/S0167-6393(02) 00084-5

Schön, D., Magne, C., and Besson, M. (2004). The music of speech: music training facilitates pitch processing in both music and language. Psychophysiology 41, 341-349. doi: 10.1111/1469-8986.00172.x

Schuetze, P., and Zeskind, P. S. (2001). Relations between women's depressive symptoms and perceptions of infant distress signals varying in pitch. Infancy 2, 483-499. doi: 10.1207/S15327078IN0204_06

Schuetze, P., and Zeskind, P. S. (2003). The perceptions of infant distress signals varying in pitch by cocaine-using mothers. Infancy 4, 6583. doi: 10.1207/s15327078in0401_4

Seifritz, E., Esposito, F., Neuhoff, J. G., Lüthi, A., Mustovic, H., Dammann, G., et al. (2003). Differential sex-independent amygdala response to infant crying and laughing in parents versus nonparents. Biol. Psychiatry 54, 1367-1375. doi: $10.1016 /$ S0006-3223(03)00697-8

Soderstrom, M. (2007). Beyond babytalk: re-evaluating the nature and content of speech input to preverbal infants. Dev. Rev. 27, 501-532. doi: 10.1016/j.dr.2007.06.002

Sohr-Preston, S. L., and Scaramella, L. V. (2006). Implications of timing of maternal depressive symptoms for early cognitive and language development. Clin. Child Fam. Psychol. Rev. 9, 65-83. doi: 10.1007/s10567-006-0004-2

Soltis, J. (2004). The signal functions of early infant crying. Behav. Brain Sci. 27, 443-458. doi: 10.1017/S0140525X0400010X

Stallings, J., Fleming, A. S., Corter, C., Worthman, C., and Steiner, M. (2001). The effects of infant cries and odors on sympathy, cortisol, and autonomic responses in new mothers and nonpostpartum women. Parent. Sci. Pract. 1, 71-100. doi: $10.1080 / 15295192.2001 .9681212$

Stein, A., Malmberg, L. E., Sylva, K., Barnes, J., Leach, P., and Team, F. C. C. C. (2008). The influence of maternal depression, caregiving, and socioeconomic status in the post-natal year on children's language development. Child Care Health Dev. 34, 603-612. doi: 10.1111/j.1365-2214.2008.00837.x

Stein, A., Woolley, H., Senior, R., Hertzmann, L., Lovel, M., Lee, J., et al. (2006). Treating disturbances in the relationship between mothers with bulimic eating disorders and their infants: a randomized, controlled trial of video feedback. Am. J. Psychiatry 163, 899-906. doi: 10.1176/appi.ajp.163. 5.899

Stifter, C. A., Bono, M., and Spinrad, T. (2003). Parent characteristics and conceptualizations associated with the emergence of infant colic. J. Reprod. Infant Psychol. 21, 309-322. doi: 10.1080/02646830310001622123

Strait, D. L., Kraus, N., Skoe, E., and Ashley, R. (2009). Musical experience promotes subcortical efficiency in processing emotional vocal sounds. Ann. N. Y. Acad. Sci. 1169, 209-213. doi: 10.1111/j.1749-6632.2009.04864.x

Thompson, W. F., Schellenberg, E. G., and Husain, G. (2004). Decoding speech prosody: do music lessons help? Emotion 4, 46-64. doi: 10.1037/15283542.4.1.46 
Trehub, S. E. (2001). Musical predispositions in infancy. Ann. N. Y. Acad. Sci. 930, 1-16. doi: 10.1111/j.1749-6632.2001.tb05721.x

Trimmer, C. G., and Cuddy, L. L. (2008). Emotional intelligence, not music training, predicts recognition of emotional speech prosody. Emotion 8, 838-849. doi: $10.1037 / \mathrm{a} 0014080$

Voorthuis, A., Riem, M. M. E., Van Ijzendoorn, M. H., and BakermansKranenburg, M. J. (2014). Reading the mind in the infant eyes: paradoxical effects of oxytocin on neural activity and emotion recognition in watching pictures of infant faces. Brain Res. 1580, 151-159. doi: 10.1016/j.brainres.2013. 10.051

Vuust, P., Brattico, E., Seppänen, M., Näätänen, R., and Tervaniemi, M. (2012). The sound of music: differentiating musicians using a fast, musical multifeature mismatch negativity paradigm. Neuropsychologia 50, 1432-1443. doi: 10.1016/j.neuropsychologia.2012.02.028

Wakabayashi, A., Baron-Cohen, S., Wheelwright, S., Goldenfeld, N., Delaney, J., Fine, D., et al. (2006). Development of short forms of the Empathy Quotient (EQ-Short) and the Systemizing Quotient (SQ-Short). Pers. Individ. Dif. 41, 929-940. doi: 10.1016/j.paid.2006.03.017

Wallentin, M., Nielsen, A. H., Friis-Olivarius, M., Vuust, C., and Vuust, P. (2010). The Musical Ear Test, a new reliable test for measuring musical competence. Learn. Individ. Differ. 20, 188-196. doi: 10.1016/j.lindif.2010.02.004

Wang, Y. P., and Gorenstein, C. (2013). Psychometric properties of the Beck Depression Inventory-II: a comprehensive review. Rev. Bras. Psiquiatr. 35, 416431. doi: 10.1590/1516-4446-2012-1048

Weisman, O., Zagoory-Sharon, O., and Feldman, R. (2014). Oxytocin administration, salivary testosterone, and father-infant social behavior. Prog. Neuropsychopharmacol. Biol. Psychiatry 49, 47-52. doi: 10.1016/j.pnpbp.2013. 11.006

Wright, B. A., and Sabin, A. T. (2007). Perceptual learning: how much daily training is enough? Exp. Brain Res. 180, 727-736. doi: 10.1007/s00221-0070898-z

Wood, R. M., and Gustafson, G. E. (2001). Infant crying and adults' anticipated caregiving responses: acoustic and contextual influences. Child Dev. 72, 12871300. doi: 10.1111/1467-8624.00348
Young, K. S., Parsons, C. E., Stein, A., and Kringelbach, M. L. (2012). Interpreting infant vocal distress: the ameliorative effect of musical training in depression. Emotion 12, 1200-1205. doi: 10.1037/a0028705

Zeskind, P. S., and Collins, V. (1987). Pitch of infant crying and caregiver responses in a natural setting. Infant Behav. Dev. 10, 501-504. doi: 10.1016/0163-6383(87) 90046-4

Zeskind, P. S., and Lester, B. M. (1978). Acoustic features and auditory perceptions of the cries of newborns with prenatal and perinatal complications. Child Dev. 49, 580-589. doi: 10.2307/1128224

Zeskind, P. S., and Marshall, T. R. (1988). The relation between variations in pitch and maternal perceptions of infant crying. Child Dev. 59, 193-196. doi: 10.2307/1130401

Zeskind, P. S., Weitsen, D., and Marshall, T. (1995). Effects of experimental manipulations of fundamental frequency on adults' perceptions of infant cry sounds. Paper Presented at the Biennial Meeting of the Society for Research in Child Development, Indianapolis, IN.

Conflict of Interest Statement: The authors declare that the research was conducted in the absence of any commercial or financial relationships that could be construed as a potential conflict of interest.

Received: 08 October 2014; accepted: 25 November 2014; published online: 19 December 2014.

Citation: Parsons CE, Young KS, Jegindø E-ME, Vuust P, Stein A and Kringelbach ML (2014) Music training and empathy positively impact adults' sensitivity to infant distress. Front. Psychol. 5:1440. doi: 10.3389/fpsyg.2014.01440

This article was submitted to Emotion Science, a section of the journal Frontiers in Psychology.

Copyright (c) 2014 Parsons, Young, Jegindø, Vuust, Stein and Kringelbach. This is an open-access article distributed under the terms of the Creative Commons Attribution License (CC BY). The use, distribution or reproduction in other forums is permitted, provided the original author(s) or licensor are credited and that the original publication in this journal is cited, in accordance with accepted academic practice. No use, distribution or reproduction is permitted which does not comply with these terms. 